\title{
Primary bacterial pathogens in bottlenose dolphins Tursiops truncatus: needles in haystacks of commensal and environmental microbes
}

\author{
Stephanie Venn-Watson ${ }^{1,2, *}$, Cynthia R. Smith ${ }^{1,2}$, Eric D. Jensen ${ }^{1}$ \\ ${ }^{1}$ United States Navy Marine Mammal Program, Space and Naval Warfare Systems Center, San Diego, 53560 Hull Street, \\ San Diego, California 92152, USA \\ ${ }^{2}$ Software Systems, Inc., 4250 Pacific Highway, Suite 125, San Diego, California 92110, USA
}

\begin{abstract}
Bacterial cultures of marine mammal samples often yield multiple genera and species, and it can be difficult to determine if a cultured bacterium is a primary pathogen or an incidental finding. To determine the relative risk of bacterial isolates among Atlantic bottlenose dolphins Tursiops truncatus at the United States Navy Marine Mammal Program (MMP), retrospective data on isolates cultured during June 1987 through June 2007 were organized into a novel, 5-tier risk categorization system limited to sole bacteria cultured from internal organ or fluid samples. Of 2586 bacterial isolates cultured, only $34(1.3 \%)$ and $25(1.0 \%)$ were sole isolates attributed to morbidity and mortality, respectively, and only $19(0.7 \%)$ isolates were associated with mortalities without evidence of fungal or viral co-infections. Highest risk bacterial isolates were most likely to be identified in pleural fluid (33.3\% of pleural fluid samples with bacterial isolates had only one genus), followed by renal (23.1\%) and splenic $(11.1 \%)$ tissue. Sole Staphylococcus aureus isolates were identified as the highest risk bacterial pathogens in the MMP dolphin population, accounting for $0.4 \%$ of total bacterial isolates over a 20 yr period. In summary, isolation of sole bacterial isolates definitively associated with morbidity and mortality in marine mammals was uncommon in the MMP population. Our proposed risk categorization system may be useful in determining high risk pathogens among other marine mammal populations.
\end{abstract}

KEY WORDS: Bacterial pathogens $\cdot$ Bottlenose dolphin $\cdot$ Staphylococcus aureus $\cdot$ Tursiops truncatus

\section{INTRODUCTION}

Parallels between humans and bottlenose dolphins Tursiops truncatus have been reported, including high brain-to-mass ratios (Wood \& Evans 1980, Marino 1998), red blood cell glucose transport systems (Craik et al. 1998), and diabetes-like metabolism in the fasting state (Venn-Watson \& Ridgway 2007). Genetic sequence comparisons of pathogens have demonstrated close relationships among those affecting humans and dolphins, including measles and dolphin morbillivirus (Wang et al. 2003), human parainfluenza type 3 and $T$. truncatus parainfluenza type 1 (Nollens et al. 2008), and Lacazia loboi, the etiology of lobomy- cosis (Herr et al. 2001). As such, improved knowledge of dolphin pathogens may provide insight into the pathology, evolution, and treatment of those affecting humans.

Despite numerous bacterial infections reported in bottlenose dolphin case reports (Dunn et al. 2001), extensive risk assessments of bacterial pathogens among dolphin populations have been challenging due to bacterial overgrowth and contamination associated with postmortem decomposition, non-sterile fields for sample collection, aspirated ocean water at the time of death, oronasal, gastric, and epidermal samples contaminated with ocean water, and fecal samples containing bacteria that may be associated with ingested fish 
and commensal flora. As such, investigators are often faced with long lists of bacterial isolates from marine mammal samples that may be primary bacterial pathogens, opportunistic bacterial pathogens, harmless commensal organisms, or environmental contaminants from an aquatic environment hosting an estimated 60000 to 153 million viral particles per milliliter of water and a 0.3 to 0.97 bacterial abundance to viral load ratio (Howard et al. 1983, Wommack \& Colwell 2000).

For nearly $50 \mathrm{yr}$, the United States Navy Marine Mammal Program (MMP) has housed and cared for a population of bottlenose dolphins living in open-ocean enclosures. These animals are fed and cared for by the MMP throughout their lives, and extensive health histories are known. Bacterial cultures and blood panels are often included in routine and clinical physical examinations. Clinical workups may include fine needle aspirates and bronchioalveolar lavage (BAL) samples; necropsies are conducted within minutes to hours of animal death limiting post-mortem bacterial overgrowth, and tissue sets are routinely submitted for histopathological examination and bacterial culture. As such, the MMP can use blood results, physical examinations, animal history, and histopathology to characterize the risk of bacteria cultured from dolphin samples.

To assess the relative risk of various bacterial microbes to dolphin health, 20 yr (1987 to 2007) of MMP bacterial isolate reports were retrospectively examined and matched to a newly proposed risk categorization system. Given parallels among dolphins and humans related to pathogens and physiology, a literature review was conducted to assess the clinical relevance of the highest risk bacterial pathogens to human health.

\section{MATERIALS AND METHODS}

MMP dolphins are housed in open ocean, netted enclosures in San Diego Bay, California, USA. They are fed a variety of quality-controlled, frozen thawed fish, including mackerel, capelin, herring, and squid. In addition to fish, dolphins are provided with daily vitamin supplements and quarterly antihelmenthics.

Prior to blood draws, sample sites were cleansed using 3 scrubs of betadine and alcohol. Approximately 30 to $40 \mathrm{ml}$ blood per sample was collected from the caudal peduncle vein using a 19 or 21 gauge 1.5 inch $(3.8 \mathrm{~cm})$ Vacutainer ${ }^{\circledR}$ needle (Becton Dickinson VACUTAINER Systems) or from a fluke vein using a 19 or 21 gauge $3 / 4$ inch $(1.9 \mathrm{~cm})$ butterfly needle and collected into glass, aerobic and anaerobic sterile bacterial blood culture bottles. Swab samples (e.g. fecal, genital, and oropharyngeal) were collected using BD
CultureSwab Plus ${ }^{\mathrm{TM}}$ with gel, and non-blood fluids (e.g. urine) and tissues were collected using sterile containers. Before shipping, whole blood samples were maintained at room temperature, and swabs, non-blood fluids, and tissues were maintained at refrigerator temperature. Samples were delivered to Quest Diagnostics Laboratory (San Diego, California), a human diagnostic reference laboratory, within $12 \mathrm{~h}$ of collection. Sterile sample collection techniques were used whenever appropriate and feasible.

In general, aerobic bacterial cultures were conducted using routine plates, including blood agar, chocolate agar, and McConkey agar; anerobic cultures were conducted using kanamycin/vancomycin agar, phenylethyl alcohol agar, and fastidious anaerobic agar incubated for at least $72 \mathrm{~h}$ and up to 1 mo for Brucella and other slow growers. While dolphin-specific PCR assays are currently used to test for suspect Brucella infection cases, this technology did not become a routine diagnostic tool until 2007. Cultures for Vibrio spp. were routinely requested from samples.

MMP medical records were reviewed for bacterial isolate reports and associated animal information (animal identifier, age, sex, sample source, sample collection date, veterinary observations, white blood cell counts, and histopathology) from bottlenose dolphins, June 1987 through June 2007. Only isolates in which a genus was successfully identified were included in the study. Bacterial isolates considered least likely to be marine environmental contaminants and more likely to be pathogenic in dolphins were defined as those isolated from dolphins in which (1) mixed bacterial isolates were not identified in the sample, and (2) isolation was from an internal organ tissue or fluid (blood, urine, or cavity fluid). Bacterial isolates from neonates and young calves (dolphins aged less than $3 \mathrm{mo}$ ) were excluded from the study due to the potential confounding issue of developing immune systems. Morbillivirus antibody titers are routinely monitored in the MMP population, and none of the dolphins in the study had evidence of active morbillivirus infection throughout the duration of the $20 \mathrm{yr}$ study period.

Bacteria that met the above inclusion criteria were characterized as associated or not associated with the following 5 categories: (1) grossly abnormal tissue or relevant clinical signs; (2) abnormal histopathology or white blood cell count indicative of a bacterial infection (e.g. neutrophilic leukocytosis); (3) confirmed or strongly suspected etiology of morbidity as assessed by an attending veterinarian: (4) confirmed or strongly suspected etiology of mortality as assessed by a pathologist; and (5) no evidence of viral or fungal co-infection found on histopathology or other diagnostic tools. If a specific pathogen was suspected on histopathology, an appropriate combination of special stains, immuno- 
histochemistry, and PCR was used to confirm the diagnosis. If validated, dolphin-specific ELISAs were available to test for antibodies to suspected pathogens; these tests were used by the veterinarians to confirm etiologies of disease.

In order for a bacterial isolate to be associated with one category, it had to meet criteria of the previous categories (e.g. a Category 4 isolate had to be associated with Categories 1 through 3, as well as being a confirmed or strongly suspected cause of mortality). Thus, higher category numbers were associated with higher risk to dolphins. A literature review was conducted on Category 5 isolates to assess the comparative role of pathogenesis in human populations, and the original dataset of bacterial isolates was reanalyzed to test for prevalence of Category 5 isolates among mixed cultures.
Table 1. Tursiops truncatus. Sample sources and frequencies of sole bacterial isolates in bottlenose dolphins, June 1987-June 2007. Cat.: Category

\begin{tabular}{|c|c|c|c|}
\hline \multirow[t]{2}{*}{ Sample source } & \multirow{2}{*}{$\begin{array}{l}\text { Total samples } \\
\text { with bacterial } \\
\text { isolates }\end{array}$} & \multicolumn{2}{|c|}{ No. of samples (\% total) } \\
\hline & & $\begin{array}{c}\text { With sole } \\
\text { bacterial isolate }\end{array}$ & $\begin{array}{c}\text { With sole Cat. } 4 \\
\text { or } 5 \text { isolate }\end{array}$ \\
\hline Bone & 1 & $1(100)$ & $0(0)$ \\
\hline Brain & 1 & 1 (100) & $0(0)$ \\
\hline Bladder & 2 & $1(50)$ & $0(0)$ \\
\hline Kidney & 13 & $5(38.5)$ & $3(23.1)$ \\
\hline $\begin{array}{l}\text { Bronchioalveolar } \\
\text { lavage }\end{array}$ & 8 & $3(37.5)$ & $0(0)$ \\
\hline Pleural fluid & 6 & $2(33.3)$ & $2(33.3)$ \\
\hline Liver & 34 & $8(23.5)$ & $3(8.8)$ \\
\hline Lymph node & 26 & $5(19.2)$ & $2(7.7)$ \\
\hline Spleen & 27 & $5(18.5)$ & $3(11.1)$ \\
\hline Testicle & 6 & $1(16.7)$ & $0(0)$ \\
\hline Blood & 42 & $6(14.3)$ & $1(2.4)$ \\
\hline Spinal cord & 18 & $2(11.1)$ & $1(5.6)$ \\
\hline Urine & 37 & $4(10.8)$ & $1(2.7)$ \\
\hline Heart & 11 & $1(9.1)$ & $1(9.1)$ \\
\hline Lung & 169 & $14(8.3)$ & $8(4.7)$ \\
\hline $\begin{array}{l}\text { Peritoneal cavity/ } \\
\text { fluid }\end{array}$ & 36 & $1(2.8)$ & $0(0)$ \\
\hline Total & 437 & $60(13.7)$ & $25(5.7)$ \\
\hline
\end{tabular}

\section{RESULTS}

During June 1987 through June 2007, a total of 2586 bacterial isolates from 942 samples and 129 dolphins were reported. Of these, $60(2.3 \%)$ isolates from 60 $(6.4 \%)$ samples and $34(26.4 \%)$ dolphins met the criteria of being a sole bacterial isolate successfully characterized at the genus level from blood, urine, cavity space fluid, or internal organ tissue samples. Sole bacterial isolates were most likely to be identified in renal tissue $(38.5 \%$ of renal samples with bacterial isolates had only one genus), followed by BAL, pleural fluid, and liver tissue (Table 1). Sole Category 4 and 5 isolates were most likely to be identified in pleural fluid (33.3\% of pleural fluid samples with bacterial isolates had only 1 genus), followed by renal and splenic tissue (Table 1).

Bacterial isolates by risk category are provided in Fig. 1. Of 2586 bacterial isolates, 19 isolates $(0.7 \%)$ of 4 genera from 8 dolphins qualified as highest risk (Category 5). These isolates were confirmed or strongly suspected primary causes of mortality in individuals without evidence of fungal, viral, or parasitic co-infections. Category 5 isolates were Staphylococcus aureus (5 cases with 11 sole isolates from blood, kidney, liver [2], lung [3], pleural fluid [2], and spleen [2]), Brucella species (1 case with 1 isolate from the vertebral column), Erysipelothrix rhusiopathiae (1 case with 6 isolates from heart, kidney, liver, lung, lymph node, and spleen), and Streptococccus Group D (1 case with 1 isolate from the lung). The prevalence of Category 5 isolates among all bacteria isolated during 1987-2007 is reported in Table 2 .

Six Category 4 sole bacterial isolates from 2 genera were cultured from 4 cases. These isolates were confirmed or strongly suspected causes of mortality in dolphins but were also associated with viral or fungal co-infections. Category 4 isolates were Proteus penneri ( 2 cases with 3 sole isolates from, lung, lymph node, and spinal cord) and Pseudomonas aeruginosa ( 2 cases with 3 isolates from blood, liver, and lung). $P$. penneri (infections in both cases were associated with concurrent seroconversion for parainfluenza virus; Nollens et al. 2007a), and $P$. aeruginosa infections in both cases were associated with concurrent fungal disease.

A total of 9 bacterial isolates cultured from 8 dolphins were Category 3 isolates, including Acinetobacter lwoffi (blood), Escherichia coli (liver, urine), Fusobacterium varium (blood), Pseudomonas species (BAL fluid), Staphylococcus aureus (abdominal mass), Streptococcus Group D (urine, lung), Vibrio species (blood). These isolates were confirmed or strongly suspected to be the etiology of abnormal tissue or clinical illness. They were not, however, associated with mortality or the cause of mortality. Two of the Category 3 animals died due to non-bacterial causes but had incidental findings of mild, inflamed liver and lung tissue associated with bacterial isolates (E. coli and Streptococcus Group D, respectively). 


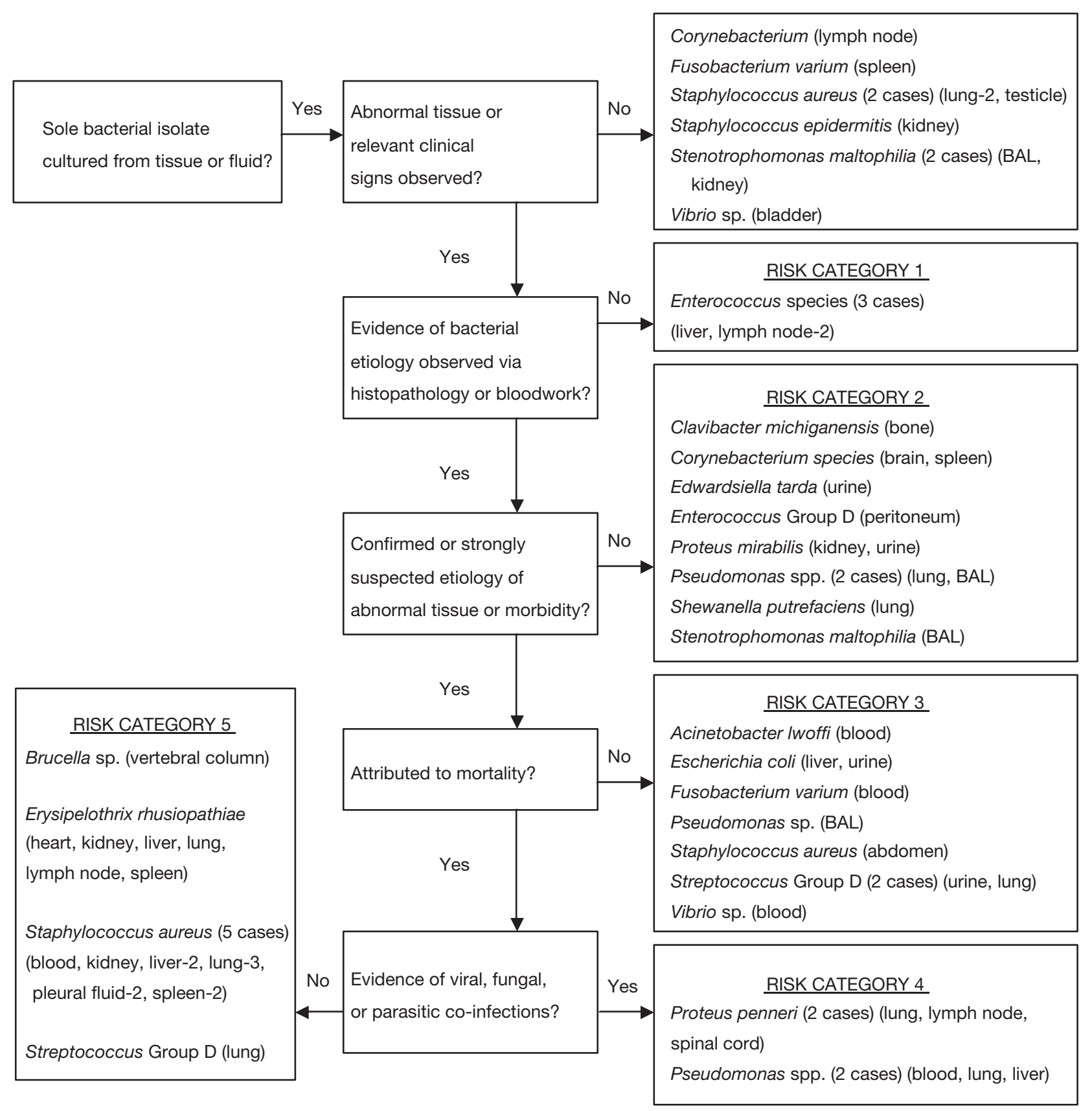

Fig. 1. Tursiops truncatus. Clinical relevance of sole bacterial isolates cultured from samples (internal organs, blood, urine, or cavity fluid) in bottlenose dolphins, 1987-2007. BAL: bronchoalveolar lavage

The following 11 Category 2 isolate genera were identified among 9 isolates using our risk categorization system: Clavibacter michiganensis (bone), Corynebacterium species (brain, spleen), Edwardsiella tarda (urine), Enterococcus Group D (peritoneum), Proteus mirabilis (kidney, urine), Pseudomonas maltophilia (lung), Shewanella putrefaciens (lung), and Stenotrophomonas maltophilia (BAL fluid). These isolates were associated with grossly and histopathologi- cally abnormal tissue or a clinically ill animal having a white blood cell count consistent with a bacterial infection. Category 2 isolates, however, were not confirmed or strongly suspected causes of morbidity.

Three Category 1 isolates, all Enterococcus species, were characterized in 3 dolphins as sole bacterial isolates cultured from grossly abnormal tissue or in an animal demonstrating clinical signs of illness. Sample sources were lymph node (2) and liver (1). Based upon 
Table 2. Tursiops truncatus. Prevalence of Category 5 bacterial genera and subtypes among all isolates, including those from mixed cultures, in bottlenose dolphins, June 1987-June 2007. N = 2586 samples. Cat.: Category

\begin{tabular}{|lcc|}
\hline \multirow{2}{*}{ Bacterium } & \multicolumn{2}{c|}{ No. of isolates } \\
\cline { 2 - 3 } & Total (\% N) & In Cat. 5 cases (\% total) \\
\hline Staphylococcus aureus & $120(4.6)$ & $44(36.7)$ \\
Brucella spp. & $13(0.5)$ & $11(84.6)$ \\
Erysipelothrix rhusiopathiae & $6(0.2)$ & $6(100)$ \\
Streptococcus Group D & $26(1.0)$ & $3(11.5)$ \\
\hline
\end{tabular}

The following 4 genera and species were identified as the highest risk primary bacterial pathogens: Staphylococcus aureus (5 individuals), Brucella species (1 individual), Erysipelothrix rhusiopathiae (1 individual), and Streptococcus Group D (1 individual). These bacteria and their associated pathologies were compared among dolphin and human populations.

Staphylococcus aureus are Grampositive cocci that thrive on skin and mu-

white blood cell count at the time of illness and postmortem histologic evaluation, however, active bacterial infections by these microbes were not evident in these tissues.

\section{DISCUSSION}

Of 2586 bacterial isolates cultured from bottlenose dolphin samples during 1987 to 2007, only 1.3 and $1.0 \%$ were sole isolates strongly suspected to be or definitively associated with morbidity and mortality, respectively. While cultures are often used to attempt disease diagnosis in dolphins (Geraci \& Lounsbury 2005), mixed growth of bacteria often makes it difficult to differentiate among clinically significant isolates, commensal organisms, and environmental contaminants (Dunn et al. 2001).

Standardized risk categorization systems have been a valuable tool for communicating relative risks for many health issues, including classes of drugs for pregnant women (Briggs et al. 2002) and biological agent risks to human populations (Centers for Disease Control and Prevention 2007). In our study, application of a standardized, 5-tier categorization system to a large retrospective dataset of bacterial isolates quickly enabled paring to a small number of isolates of greatest clinical interest. As such, this system may be beneficial for future bacterial risk assessments involving marine mammals living in a variety of environments, including managed dolphins living in closed water systems or wild dolphins living in the open ocean.

Given the likelihood of mixed bacterial growth from marine mammal samples, our study indicated that samples most likely to yield sole bacterial pathogens were antemortem pleural fluid, blood, and BAL fluid, and postmortem pleural fluid, kidney, and splenic tissues. These findings may be used to help refine existing sampling protocols for bacterial diagnostics in marine mammals (Geraci \& Lounsbury 2005) and may decrease the frequency of less helpful samples, such as blowhole and fecal swab bacterial cultures. cocutaeous surfaces of numerous terrestrial animals, including humans. As reported in other managed dolphin populations (Kinoshita et al. 1994), highest risk S. aureus infections were most often associated with pneumonia and septicemia. In the United States, S. aureus is the leading cause of nosocomial pneumonia and the second leading cause of nosocomial bloodstream infections in humans (Centers for Disease Control and Prevention 2004). Respiratory-associated $S$. aureus infections in other mammals are limited (Biberstein \& Hirsh 1999). Interspecies transmission of $S$. aureus is rare (Biberstein \& Hirsh 1999), and $S$. aureus isolates compared between dolphins and oceanarium personnel demonstrated marked differences in antimicrobial resistance and subtypes (Streitfeld \& Chapman 1976), indicating that cross infection between dolphins and personnel did not occur. Comparisons of primate and cetacean $S$. aureus molecular sequences, respiratory physiology, and respiratory anatomy may be of interest to assess why lung infections appear to be more prevalent in these 2 genera compared to other animal genera.

Brucella is a Gram-negative, fastidious bacterium associated with disease in various terrestrial mammals, including humans. We report one dolphin with Brucella-associated vertebral osteomyelitis. Elevated Brucella antibody titers were detected in this animal antemortem using an indirect, dolphin-specific enzymelinked immunosorbent assay, and polymerase chain reaction assays detected Brucella species. During the past $10 \mathrm{yr}$, isolation of Brucella species from a wide variety of marine mammal species have been well documented (Alexander et al. 1989, Foster et al. 1996, Miller et al. 1999), and serological studies have demonstrated a high global prevalence of exposure to this bacterium (Tryland et al. 1999, Nielsen et al. 2001). Marine-associated Brucella species have been associated, although rarely, with community-acquired human infections, including intracerebral granulomas and vertebral osteomyelitis (Sohn et al. 2003, McDonald et al. 2006). While preliminary studies report that marine and terrestrial Brucella species are different (Bricker et al. 2000, Cloeckaert et al. 2003), more research may be needed using large sample sets of Brucella isolates 
from dolphin and human clinical samples to assess pathogenic similarities among these Brucella species.

Erysipelothrix rhusiopathiae is a Gram-positive rod associated with epidermal and systemic disease in humans, swine, sheep, and a variety of birds (Brooke \& Riley 1999). During our 20 yr study period, we report one dolphin with disseminated E. rhusiopathiae infection. Similar infections have occurred in other facilities housing bottlenose dolphins (Ridgway, 1972, Terasawa et al. 2001) and have presented a risk high enough to warrant vaccinations (Nollens et al. 2007). Interestingly, despite similar fish food supplies among facilities housing bottlenose dolphins, the MMP population has not appeared to be susceptible to E, rhusiopathiaeassociated epizootics.

Streptococcus Group D is a Gram-positive coccus primarily associated with endocarditis and bacteremia in humans (Bayer \& Scheld 2000). The most common type of Streptococcus Group D affecting humans is S. bovis. We report one dolphin with Streptococcus Group D associated pneumonia. Extensive published reports were not found related to Streptococcus Group D infections in bottlenose dolphins, and similarities of Streptococcus Group D isolates among dolphins and humans is unknown.

Over a 20 yr period, no Category 5 infections occurred within a short period of time among dolphins, indicating that sole bacterial primary pathogens are not a significant cause of mortality-associated epizootics in our population. MMP dolphins may be less susceptible to severe bacterial disease than wild dolphins due to early and effective treatment of bacterial infections and the practice of a vigilant preventive medicine program at the MMP. Additionally, MMP dolphins may be less susceptible to bacterial disease than other collection dolphins housed in relatively sterile, closed water systems, due to routinely stimulated immune systems from an environment naturally laden with a variety of bacteria and viruses (Carmack et al. 2007). While MMP dolphins may travel to remote places, there was no evidence that bacterial infections were uniquely acquired in waters beyond San Diego.

Our study was limited by using a risk categorization system relying upon sole bacterial isolates identified from internal organs and fluids, thus eliminating the opportunity to identify mixed bacterial infections or infections that may have been detected from epidermal, fecal, and oronasal samples in our population. The same risk categorization system could be applied to assess the significance of mixed, epidermal, and oronasal bacterial infections, but more histopathologic examinations are needed on affected tissues of live animals. A long-term study comparing fecal bacterial populations among dolphins that are healthy and those with gastrointestinal signs may also help to differentiate between pathogenic and commensal organisms.
While all 4 Category 5 genera and species identified in our study were the same or similar to bacteria that cause illness in humans, all of our dolphin samples were cultured for bacteria in a standard reference laboratory. As such, terrestrial versus marine bacteria genera were more likely to be successfully typed. Use of molecular diagnostics on future samples will greatly improve the ability to characterize unculturable bacterial pathogens affecting dolphins. Finally, our study was limited due to clinical samples that were submitted for bacterial culture from individuals being treated with antibiotics, decreasing the chance of isolating some bacteria.

In summary, we proposed and implemented a standardized risk categorization system limited to sole isolates from internal organs and fluids. Despite culturing thousands of bacterial isolates from many bottlenose dolphin samples over a 20 yr period, isolation of sole, primary bacterial pathogens was rare. To further prevent these rare primary infections, however, it would be useful to conduct additional studies to assess predisposing risk factors for Category 4 and 5 isolate infections, including skin wounds or other portals for infection.

Due to the overlap of our 4 highest risk bacterial genera identified in dolphins with those affecting human populations, a better understanding of dolphin bacterial pathogens may benefit human research and public health. While oronasal (blowhole), epidermal, and fecal swabs were of limited use in this study due to mixed-bacterial growth, these samples continue to be useful for detecting viruses, parasites, and evidence of regional inflammation.

Acknowledgements. Thanks to S. H. Ridgway, W. G. Miller, P. Schroeder, and W. Van Bonn for their early efforts related to bacterial cultures at the United States Navy Marine Mammal Program (MMP). Thanks also to C. Lomax, R. Daniels, and K. Carlin, and Quest Diagnostics Laboratories for submitting and processing samples.

Ethics. The MMP is accredited by the Association for Assessment and Accreditation of Laboratory Animal Care International and adheres to the national standards of the United States Public Health Service Policy on the Humane Care and Use of Laboratory Animals and the Animal Welfare Act. As required by the Department of Defense, the Navy MMP's animal care and use program is routinely reviewed by an Institutional Animal Care and Use Committee and the Department of Defense Bureau of Medicine.

\section{LITERATURE CITED}

Alexander JW, Solangi MA, Riegel LS (1989) Vertebral osteomyelitis and suspected diskospondylitis in an Atlantic bottlenose dolphins (Turiops truncatus). J Wildl Dis 25:118-121

Bayer AS, Scheld WM (2000) Endocarditis and intravascular infections. In: Mandell GL, Bennett JE, Dolin R (eds) Man- 
dell, Douglas, and Bennett's principles and practice of infectious disease, Vol 1, 5th edn. Churchill Livingstone, Philadelphia, PA, p 857-902

Biberstein EL, Hirsh DC (1999) Staphylococci. In: Hirsh DW, Zee YC (eds) Veterinary microbiology. Blackwell Science, Ames, IA, p 115-119

Bricker BJ, Ewalt DR, MacMillan AP, Foster G, Brew S (2000) Molecular characterization of Brucella strains isolated from marine mammals. J Clin Microbiol 38:1258-1262

Briggs GG, Freeman RK, Yaffe SJ (2002) Drugs in pregnancy and lactation, 6th edn. Williams \& Williams, Baltimore, MD

Brooke CJ, Riley TV (1999) Erysipelothrix rhusiopathiae: bacteriology, epidemiology and clinical manifestations of an occupational pathogen. J Med Micro 48:789-799

Carmack TB, Van Bonn W, Poll C (2007) Potential implications of the hygiene hypothesis on cetacean management systems. In: Stremme DW (ed) Proceedings of the 38th Annual Conference, International Association for Aquatic Animal Medicine. Lake Buena Vista, FL, p 156-157

Centers for Disease Control and Prevention (2004) National nosocomial infections surveillance (NNIS) system report, data summary from January 1992 through June 2004, issued October 2004. Am J Infect Control 32:470-485

Centers for Disease Control and Prevention (2007) Bioterrorism agents/diseases by category. Available at: http:// emergency.cdc.gov/agent/agentlist-category.asp

Cloeckaert A, Grayon M, Grepinet O, Boumedine KS (2003) Classification of Brucella strains isolated from marine mammals by infrequent restriction site PCR and development of specific PCR identification tests. Microbes Infect 5:593-602

Craik JD, Young JD, Chesseman CI (1998) GLUT-1 mediation of rapid glucose transport in dolphin (Tursiops truncatus) red blood cells. Am J Physiol 274:R112-R119

Dunn JL, Buck JD, Robeck TR (2001) Bacterial diseases of cetaceans and pinnipeds In: Dierauf LA, Gulland FMD (eds) CRC handbook of marine mammal medicine, 2nd edn. CRC Press, Boca Raton, FL, p 309-328

Foster G, Reid RJ, Ross HM, Jahans KL (1996) Isolation of Brucella species from cetaceans, seals, and an otter. Vet Rec 138:583-586

Geraci JR, Lounsbury VJ (2005) Specimen and data collection In: Geraci JR , Lounsbury VJ (eds) Marine mammals ashore: a field guide for strandings, 2nd edn. National Aquarium in Baltimore, Baltimore, MD, p 167-228

Herr RA, Tarcha EJ, Taborda PR, Taylor JW, Ajello L, Mendoza L (2001) Phylogenetic analysis of Lacazia loboi places this previously uncharacterized pathogen within the dimorphic onygenales. J Clin Microbiol 39:309-314

Howard EB, Britt JO, Matsumoto GK, Itahara R, Nagano CN (1983) Bacterial diseases. In: Howard EB (ed) Pathobiology of marine mammal diseases, Vol. 1. CRC Press, Boca Raton, FL, p 69-118

Kinoshita R, Brook F, Vedros N, Wad HS and others (1994) Staphylococcal isolations and clinical cases of Staphylococcus aureus in bottlenose dolphins at Ocean Park, Hong

Editorial responsibility: Michael Moore, Woods Hole, Massachussetts, USA
Kong. In: Fenwick B (ed) Proceedings of the 25th Annual Workshop of the International Association for Aquatic Animal Medicine. Vallejo, CA, p 159

Marino L (1998) A comparison of encephalization between odontocete cetaceans and anthropoid primates. Brain Behav Evol 51:230-238

$>$ McDonald WL, Jamaludin R, Mackereth G, Hansen M and others (2006) Characterization of a Brucella sp. strain as a marine-mammal type despite isolation from a patient with spinal osteomyelitis in New Zealand. J Clin Microbiol 44:4363-4370

Miller WG, Adams LG, Ficht TA, Cheville NF and others (1999) Brucella-induced abortions and infection in bottlenose dolphins (Tursiops truncatus). J Zoo Wildl Med 30:100-110

Nielsen O, Stewart RE, Nielsen K, Measures L, Duignan P (2001) Serologic survey of Brucella spp. antibodies in some marine mammals of North America. J Wildl Dis 37:89-100

Nollens HH, Green LG, Duke D, Walsh MT and others (2007) Development and validation of monoclonal and polyclonal antibodies for the detection of immunoglobulin $\mathrm{G}$ of bottlenose dolphins (Tursiops truncatus). J Vet Diagn Invest 19:465-470

Nollens HH, Wellehan JX, Saliki JT, Caseltine SL, Jensen ED, Van Bonn W, Venn-Watson S (2008) Characterization of a parainfluenza virus isolated from a bottlenose dolphin (Tursiops truncatus). Vet Microbiol 128:231-242

Ridgway SH (1972) Homeostasis in the aquatic environment. In: Ridgway SH (ed) Mammals of the sea: biology and medicine. Charles C Thomas Publisher, Springfield, IL, p 701

Sohn AH, Probert WS, Glaser CA, Gupta N and others (2003) Human neurobrucellosis with intracerebral granuloma caused by a marine mammal Brucella spp. Emerg Infect Dis 9:485-488

Streitfeld MM, Chapman CG (1976) Staphylococcus aureus infections of captive dolphins (Tursiops truncatus) and oceanarium personnel. Am J Vet Res 37:303-305

Terasawa F, Kataoka Y, Sawada T, Takahashi K, Kitamura M, Fujimoto A (2001) Two cases of Erysipelothrix rhusiopathiae serotype 2 infection in bottlenose dolphins. Jpn J Zoo Wildl Med 6:67-71

Tryland M, Kleivane L, Alfredsson A, Arnason A, Stuen S, Godfroid J (1999) Evidence of Brucella infection in marine mammals in the North Atlantic Ocean. Vet Rec 144: 588-592

- Venn-Watson SK, Ridgway SH (2007) Big brains and blood glucose: common ground for diabetes mellitus in humans and healthy dolphins. Comp Med 57:390-395

> Wang LF, Chua KB, Yu M, Eaton BT (2003) Genome diversity of emerging paramyxoviruses. Curr Genomics 4:263-273

> Wommack KE, Colwell RR (2000) Virioplankton: viruses in aquatic ecosystems. Microbiol Mol Biol Rev 64:69-114

Wood FG, Evans WE (1980) Adaptiveness and ecology of echolocation in toothed whales. In: Busnel C, Fish J (eds) Animal sonar systems. Plenum Press, New York, p 381-426

Submitted: November 14, 2007; Accepted: January 15, 2008 Proofs received from author(s): March 18, 2008 